Original Article

\title{
INDUCTION OF AUTOPHAGY IN HUMAN CERVICAL CANCER CELL LINE (SIHA) BY CHAETOMORPHA LINUM (MULLER) KÜTZ.
}

\author{
INDIRA MAJUMDER ${ }^{1}$, SUBHABRATA PAUL ${ }^{1}$, RITA KUNDU ${ }^{1 *}$ \\ ${ }^{1}$ Department of Botany, Centre of Advanced Study, University of Calcutta, 35, Ballygunge Circular Road, Kolkata 700019, India \\ Email: kundu_rita@yahoo.co.in
}

Received: 02 Jan 2018 Revised and Accepted: 30 Apr 2018

\begin{abstract}
Objective: Algae is a rich source of various metabolites. Use of algae in traditional medicine was reported from very early days. The potential anticancerous activity of the algae was also reported by recent researches. In the present study, cell death mechanism induced by green alga Chaetomorpha linum (Muller) Kütz. was studied on human cervical cancer cell line, SiHa (Human papilloma virus-HPV 16+ve).

Methods: Cells were treated with chloroform fraction of the Chaetomorpha linum (CLC). DNA fragmentation, cell proliferation, nuclear morphology, localization of autophagosomes and expression of relevant proteins were studied. Cell cycle and mitochondrial membrane potential (MMP) were assessed by fluorescence assisted cell sorting (FACS). Gas chromatography liquid spectrometry (GCMS) analysis of CLC was done to detect the algal compounds.

Results: Preliminary experiments confirmed the absence of DNA fragmentation and altered nuclear morphology in the treated cells. In the Acridine Orange stained cells, the presence of autophagosomes was observed by both microscopy and FACS analysis. Decreased MMP was observed in the treated sets. Wound healing assay showed the inhibitory activity of CLC on SiHa cells. Increased expression of autophagic proteins, viz; LC3BII, p62/SQSTM, Beclin-1 and decreased expression of S6 were observed in the treated sets; indicating that autophagic cell death was induced. Preliminary qualitative chemical study and GCMS analysis detected the presence of saponins, glycosides, alkaloids, phenols, steroids and fatty acids in CLC.
\end{abstract}

Conclusion: All these findings clearly suggested that the chloroform fraction of the algae was responsible for induction of apoptosis followed by autophagic cell death in SiHa and can serve as a potential candidate for anticancer drug development in future.

Keywords: Chaetomorpha, SiHa cell line, Autophagy, Western blot analysis, LC3B, GCMS

(C) 2018 The Authors. Published by Innovare Academic Sciences Pvt Ltd. This is an open access article under the CC BY license (http://creativecommons.org/licenses/by/4.0/) DOI: http://dx.doi.org/10.22159/ijpps.2018v10i6.24593

\section{INTRODUCTION}

Marine macroalgae are considered as a good source of several unique natural products, having pharmaceutical and biological activities [1]. An array of compounds was produced by the algae to protect themselves from other organisms as well as from the adverse environment. Alkaloids, polyketides, polysaccharides, diterpenoids, sterols, quinones, lipids, cyclic peptides, phlorotannins and glycerols are some of the algal metabolites commonly produced by the marine macroalgae. These compounds showed a wide range of biological activities [2]. Due to the presence of such various metabolites, algae are used as a potential source and utilized in different industries. Iodine, carotene, alginate and carrageenan are algal metabolites having been used in the pharmaceutical industry [3]. Use of algae in traditional medicine was reported from very early days and recent researchers also report their anti-bacterial, anti-leishmanial, anti-diabetic, anti-insecticidal and anti-viral activities. Ethanolic extract of Ulva showed antimicrobial and antifungal activities [4]. The potential anticancer activity of the algae was also reported. Many chlorophycean genera like Galaxaura marginata, Capsosiphon fulvescens, Caulerpa taxifolia, Cladophoropsis vaucheriaeformis, Halimeda macrobola, Ulva fasciata, Enteromorpha intestinales, Rhizoclonium riparium etc. are reported to have potent anti-cancerous activity [5-12], inducing apoptosis or other types of cell death in cell lines or in vivo model systems. Some isolated algal compounds are under clinical trials to check their therapeutic potentiality.

Cancer is the second life-threatening disease for the human population. A five-year fact sheet based on worldwide cancer cases reported about 58\% death among all types of cancer cases, Globocan report 2012 [13] also revealed increasing death percentages worldwide. The main setback of cancer therapeutics is severe side effects associated with it and affordability of the drugs. Cost effective and alternative medicines without any side effects or lesser side effects, from the natural origin, can be an alternative to combat various types of cancer.

Indian Sunderban mangrove ecosystem (SME) is very rich in marine macroalgal diversity and is highly unexplored for their antiproliferative properties. That's why the study has been undertaken to assess the efficacy of the algae in inhibiting the proliferation of cervical squamous carcinoma cells in vitro. The experimental alga was collected from SME and the antiproliferative property was tested on SiHa (HPV16 positive, HPV is responsible for causing cancer and tumorigenesis on cervix uteri) cell line. In fact, HPV 16 infection is more prevalent in Indian population.

Collected alga was initially extracted in methanol and fractionated further by petroleum ether, chloroform and water. Chloroform fractions of Chaetomorpha linum (Muller) Kütz. (CLC) was found to be the most promising fraction having selective cytotoxicity, with an $\mathrm{IC}_{50}$ dose of $247.3 \mu \mathrm{g} / \mathrm{ml}$ as reported earlier [14]. In the present study, we have tried to identify the bioactive compounds present in the CLC as well as to find out the mechanism of cell death pathway induced in $\mathrm{SiHa}$.

\section{MATERIALS AND METHODS}

\section{Chemicals and reagents}

Eagle's minimum essential media (MEM, HIMEDIA), fetal bovine serum (FBS, Gibco), antibiotic antimycotic solution (HIMEDIA, containing penicillin, streptomycin, amphotericin B), dimethyl sulphoxide(DMSO, HIMEDIA), sodium chloride ( $\mathrm{NaCl}$, Merck), ethylenediaminetetraacetic acid (EDTA, Sigma), sodium dodecyl sulfate (SDS, Sigma), nonidet P-40 (NP40, Sigma), ethidium bromide (EtBr; Sigma), propidium iodide (PI, SIGMA), poly-lysine (Sigma), hoechst 33258 (SIGMA-ALDRICH), N-propyl gallate (SIGMA), 
glycerol (Merck), Acridine orange (AO, HIMEDIA), Rhodamine 123 (Rh 123, SIGMA), ß-markaptoethanol (Sigma), protease inhibitor (GBiosciences), polyvinylidene fluoride (PVDF, Pall) membrane, bovine serum albumin (BSA, SIGMA), sodium azide (Na-azide, SIGMA), primary antibodies-p53, Caspase 3, PARP1(Santa Cruz), p62, S6, Beclin1, LC3B (Cell Signalling Technology), Caspase 9, AMPK $\alpha$ (Abcam), $\gamma$-actin(Bio-Bharti) secondary antibodies-AP conjugated (Santa Cruz), 5-nitro blue tetrazolium/bromo-4-chloro3-indolyl phosphate (NBT-BCIP, SIGMA), dichloromethane (DCM, Merck), N,O-bis (trimethylsilyl) triflouroacetamide (BSTFA, SIGMA), chloroform (Merck).

\section{Cell line maintenance and drug treatment}

SiHa cell line was obtained from National Centre for Cell Science (NCCS), Pune, India; and maintained in MEM supplemented with $10 \%$ FBS and $1 \%$ antibiotic-antimycotic solution at $37{ }^{\circ} \mathrm{C}$ in a humidified atmosphere having $5 \% \mathrm{CO}_{2}$.

Chloroform fraction of $C$. linum was air dried and dissolved in DMSO (stock concentration $100 \mu \mathrm{g} / \mu \mathrm{l}$ ). According to our previous experiment, it was found that CLC had an $\mathrm{IC}_{50}$ doses at $247.3 \mu \mathrm{g} / \mathrm{ml}$. All the experiments were conducted with this concentration.

\section{DNA fragmentation assay}

DNA fragmentation assay was undertaken to determine the type of cell death. $1 \times 10^{7}$ cells were seeded in T25 flasks and CLC was added according to $\mathrm{IC}_{50}$ doses and incubated for $24 \mathrm{~h}$ at $37^{\circ} \mathrm{C}$. DNA from the cells was extracted with lysis Buffer $(200 \mathrm{mmol} \mathrm{NaCl}, 20 \mathrm{mmol}$ Tris, $50 \mathrm{mmol}$ EDTA, 1\% SDS and 2\% NP40). DNA was precipitated with $70 \%$ ethanol, dissolved in $1 \mathrm{X} \mathrm{TE}$ and run in $1.5 \%$ of agarose gel in Tris-acetate-EDTA buffer containing EtBr $(0.5 \mu \mathrm{g} / \mathrm{ml})$ at $60 \mathrm{~V}$ and visualized under ultraviolet (UV) trans-illuminator and photographed in gel documentation system (UVP Multidoc-It).

\section{Cell cycle analysis}

During each cell cycle, DNA content varies from one phase to another. Each phase depends on regulations or checkpoints ensured by the previous one [15]. Treatment with plant extract may alter cell cycle phases and arrest cells mainly at sub G0 or G0-G1 [16-17]. For this purpose, cells treated with CLC for $24 \mathrm{~h}$, along with control sets were incubated at $37{ }^{\circ} \mathrm{C}$ and fixed with $70 \%$ ethanol. PI was used to stain DNA.

\section{Nuclear morphology study}

Fluorochrome dye, hoechst 33258 was used to study the nuclear morphology of the treated as well as untreated cells, which binds to the A-T rich region of DNA after penetrating cell membrane easily and causing an increment in fluorescence [18-19]. SiHa cells $\left(1 \times 10^{3}\right)$ grown on poly-lysine coated coverslips were treated with CLC and incubated for $24 \mathrm{~h}$. After incubation, cells were washed with PBS and stained with hoechst 33258 with a final concentration of $2 \mu \mathrm{g} / \mathrm{ml}$ in dark for 10 min and mounted in PBS containing 10\% glycerol, $2 \% \mathrm{~N}$ propyl gallate and visualized under darkfield fluorescence microscope (Olympus) with an excitation at $356 \mathrm{~nm}$ and emission at $465 \mathrm{~nm}$.

\section{Study of acidic compartments with Acridine Orange}

Acridine orange (AO) is an orange colored dye, cationic and lipophilic. Both microscopic and flow cytometric techniques were used to detect acidic vacuoles in CLC treated cells.

For microscopic analysis, SiHa cells were grown on poly-lysine coated coverslips and treated for $24 \mathrm{~h}$. Then the coverslips were washed and $1 \mu \mathrm{g} / \mathrm{ml}$ of $\mathrm{AO}$ was added for $10 \mathrm{~min}$ and visualized under darkfield fluorescence microscope (Olympus).

For fluorescence-activated cell sorting (FACS; BD FACSVerse) analysis, cells were seeded in T25 flasks and after treatment, cells were washed with PBS and trypsinized cell suspensions were stained with AO $(1 \mu \mathrm{g} / \mathrm{ml})$ for $10 \mathrm{~min}$ and analyzed $(550 \mathrm{~nm}$ excitation, $600 \mathrm{~nm}$ emission). FACS data for both control and treated sets were analyzed with flow logic software.

\section{Mitochondrial membrane potential assay}

Positively charged Rh123 can selectively localize into mitochondria. The altered or stressed condition causes leakage in the mitochondrial membrane, decreasing the membrane potential. Cell population with altered mitochondrial membrane potential can be measured by FACS at $507 \mathrm{~nm}$ excitation and $529 \mathrm{~nm}$ emission.

Seeded SiHa cells were trypsinized after $24 \mathrm{~h}$ of treatment with CLC; all the treated and control sets along with unstained samples were incubated with Rh $123(10 \mu \mathrm{g} / \mathrm{ml})$ for $10 \mathrm{~min}$. FACS data were analyzed with flow logic software.

\section{Western blot analysis}

For western blot analysis, $1 \times 10^{7}$ cells were seeded in T25 flasks and treated with the algal fractions for $24 \mathrm{~h}$ along with the untreated sets. In another set, cells were grown for $3 \mathrm{~h}$ in Hank's balanced salt solution (HBSS) for induction of autophagy (starvation-induced autophagy as a positive control). Confluent SiHa cells (about 80\%) were washed with chilled PBS and scrapped with a policeman. Cells were then lysed with lysis buffer containing $100 \mathrm{mmol}$ Tris- $\mathrm{HCl}(\mathrm{pH}$ 6.8), 4\% SDS, $20 \%$ glycerol and 3 -markaptoethanol and a protease inhibitor. Protein concentration was determined by the standard micro lowry method. Protein samples $(50 \mu \mathrm{g})$ were loaded and separated in SDS-PAGE (10\%), then transferred onto a PVDF membrane. Blocking buffer containing 5\% BSA in tris buffer saline (TBS) with $0.02 \%$ Na-azide was used to block the membrane for $2 \mathrm{~h}$. Primary antibodies were used with 1:500 dilutions for p53, 5' AMPactivated protein kinase $\alpha(\mathrm{AMPK} \alpha)$, Caspase 3 , Caspase 9, poly [ADP-ribose] polymerase 1 (PARP1), 1:750 dilutions for p62, S6, Beclin1;1:10000 dilutions for LC3B, $\gamma$-actin, incubated overnight at 4 ${ }^{\circ} \mathrm{C}$. After washing, secondary antibodies (alkaline phosphatase-AP conjugated) were added and incubated for $2 \mathrm{~h}$ with constant shaking. NBT-BCIP was used as a substrate to visualize the bands.

\section{Wound healing assay}

To study cell migration and proliferation on in vitro system, this assay has been used which is very cost effective and simple. It only requires a minor wound or scratch, made on monolayer cell culture and the directional cell migration at the wounded sites can be an indication of cell proliferation. A straight scratch was made with a pipette tip in each plate containing SiHa calls.

The treated set was compared with a control set after $24 \mathrm{~h}$ incubation and visualized under a compound microscope.

\section{Phytochemical screening}

\section{Qualitative screening}

Preliminary Test for phytochemicals present in CLC was determined. Presence of tannins, flavonoids, saponins, glycosides, steroids, terpenoids, alkaloids and phenols were carried out by the method after Evans et al. [20].

\section{Gas chromatography-mass spectrometry (GC-MS) analysis}

GC-MS was carried out for the identification of volatile and nonvolatile compounds present in CLC in an Agilent GCMS (7890A5975C) system interfaced to a mass spectrometer combined with GCMS chemstation and NIST library 2011. The compounds were separated on an Agilent HP5 column (30 metres $\times 0.25 \mathrm{~mm})$ with a pore size of $0.25 \mathrm{um} .1 \mu \mathrm{l}$ of the extract was inserted with the help of Agilent syringe $(10 \mathrm{ul})$ and subjected to a temperature gradient of 70-260 degree with a ramping of 5 degree/min. CLC extract was air dried and dissolved in DCM and chloroform. BSTFA was used as derivatization reagent. After washing with hexane, CLC sample was mixed with BSTFA followed by a heat treatment of $60^{\circ} \mathrm{C}$ for $30 \mathrm{~min}$. Then, $1 \mu$ of prepared sample was injected for a 50 min run. The chromatogram was compared with NIST databases which showed the presence of several compounds.

\section{Statistical analysis}

All the experiments were done in triplicate $(n=3)$. Data expressed as, mean $\pm S D$, and calculated by Microsoft Excel. Bar graphs were 
prepared by Microsoft Excel and analyzed by ANOVA (Graphpad Prism 5).

\section{RESULTS}

Bands of intact genomic DNA was observed in CLC treated (24 h) set (fig. 1), indicating non-apoptotic cell death pathway.

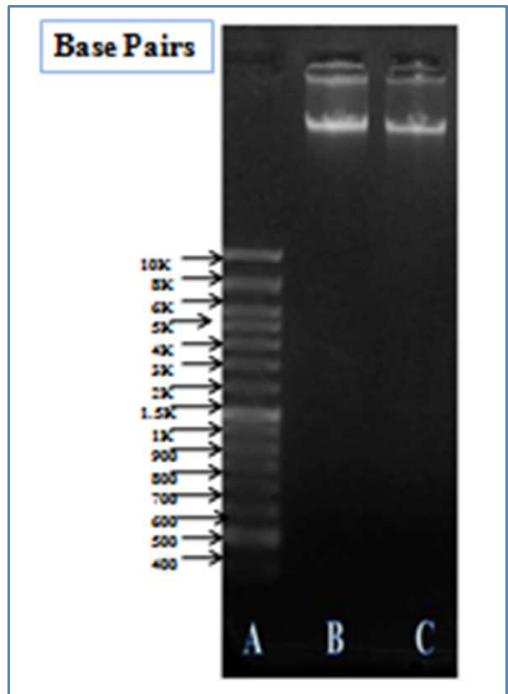

Fig. 1: DNA extracted from SiHa cells and stained with EtBr. Lanes: (A) DNA ladder (0.4 to $10 \mathrm{~kb}$ ), (B) untreated set, (C) set treated with Chaetomorpha linum chloroform fraction (CLC) Note: Extracted DNA was dissolved in 1X TE and run in 1.5\% of agarose gel in Tris-acetate-EDTA buffer

Cell cycle analysis showed a slightly increased percentage of sub G0 cells in the treated set, indicating the cytotoxic potential of CLC. Decreased percentage of cells were observed in G0-G1 phase, whereas the percentage of cells in S and G2-M phase remain unaltered (fig. 2).
Nuclear morphology was studied by hoechst staining. In the untreated sets, normal ovoid shaped nuclei were observed whereas in treated sets, condensed nuclei along with deformed nuclei were observed. In untreated sets, the numbers of viable cells were much higher than that of the treated sets (fig. 3).

Acridine orange staining assay revealed the presence of greater number of acidic compartments in extract treated sets (fig. 4). When observed under a fluorescence microscope, bright red colored dotted structures were observed in the untreated set, whereas, regions with defused red dye accumulation was observed in treated ones indicating the formation of autophagosomes.

Formation of greater number of cells with autophagosomes in treated set was also validated by the FACS analysis (fig. 5).

FACS analysis of mitochondrial membrane potential assay after Rh123 staining had shown significant changes in membrane potential. As compared with the untreated set the amount of scattered P1 population has changed significantly in the treated set (fig. 6).

Increased cell populations with quenched mitochondrial fluorescence were observed from FACS data. In CLC treated set, about fivefold increase in population was detected. This clearly indicated that mitochondrial membrane was damaged and played an important role in inducing cell death.

Lipidated form of $16 \mathrm{kd}$ protein LC3BI (microtubule-associated protein chain 3) i.e., LC3BII (18kd) is a potential marker for autophagy to study. Western blot analysis indicated increased LC3BII expression in CLC treated set and positive control set (autophagy induced by starvation) compared to untreated ones. The expression level of other autophagic proteins like Beclin1 and p62/SQSTM increased significantly in CLC treated cells. Whereas S6 protein expression level was found to be decreased. Enhanced expression of apoptotic protein p53 was also evident in treated and in positive control set, indicating its role in autophagic cell death. Though p53 is an apoptogenic protein, its influence on autophagy [21] was well reported (fig.7A). Expression of the cleaved product of AMPK $\alpha$ was found to be increased in the treated set. Along with that, cleaved products of Caspase 3 and PARP1 were also observed in the treated sets. Caspase 9 expression was also found to be increased in the treated set (fig. 7B). 3 methyladenine (3MA) was used as a negative control and $\gamma$-actin as a loading control.

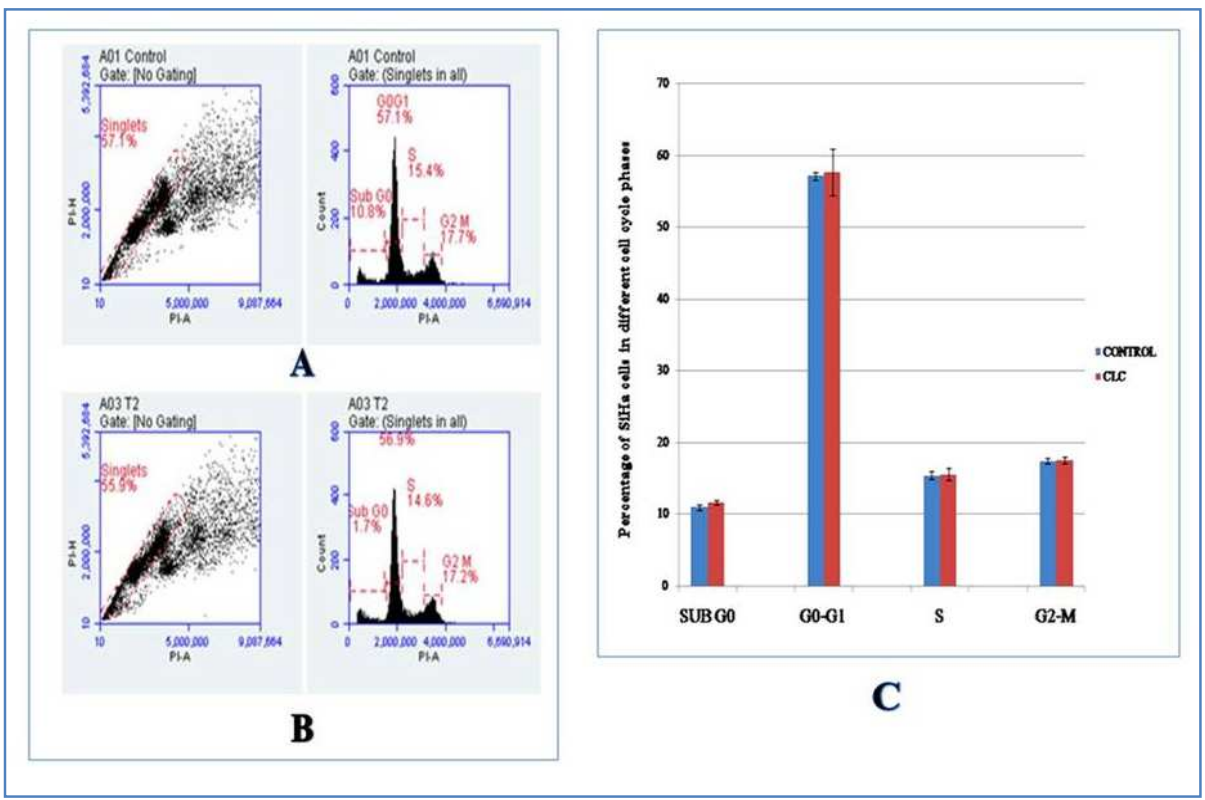

Fig. 2: Flow Cytometric analysis of cell cycle kinetics of untreated set (A), CLC treated set (B), Bar graph showing varying percentages of different cell cycle phases, Sub $G_{0}-G_{1}, G_{1}, S$ and $G_{2}+M$ phases are signified with bar area (C)

Note: SiHa cells were treated with Chaetomorpha linum chloroform fraction(CLC) for $24 \mathrm{~h}$. Values are expressed as mean \pm SD of three independent experiments ( $n=3)$. FACS data were analysed by Flowlogic software 


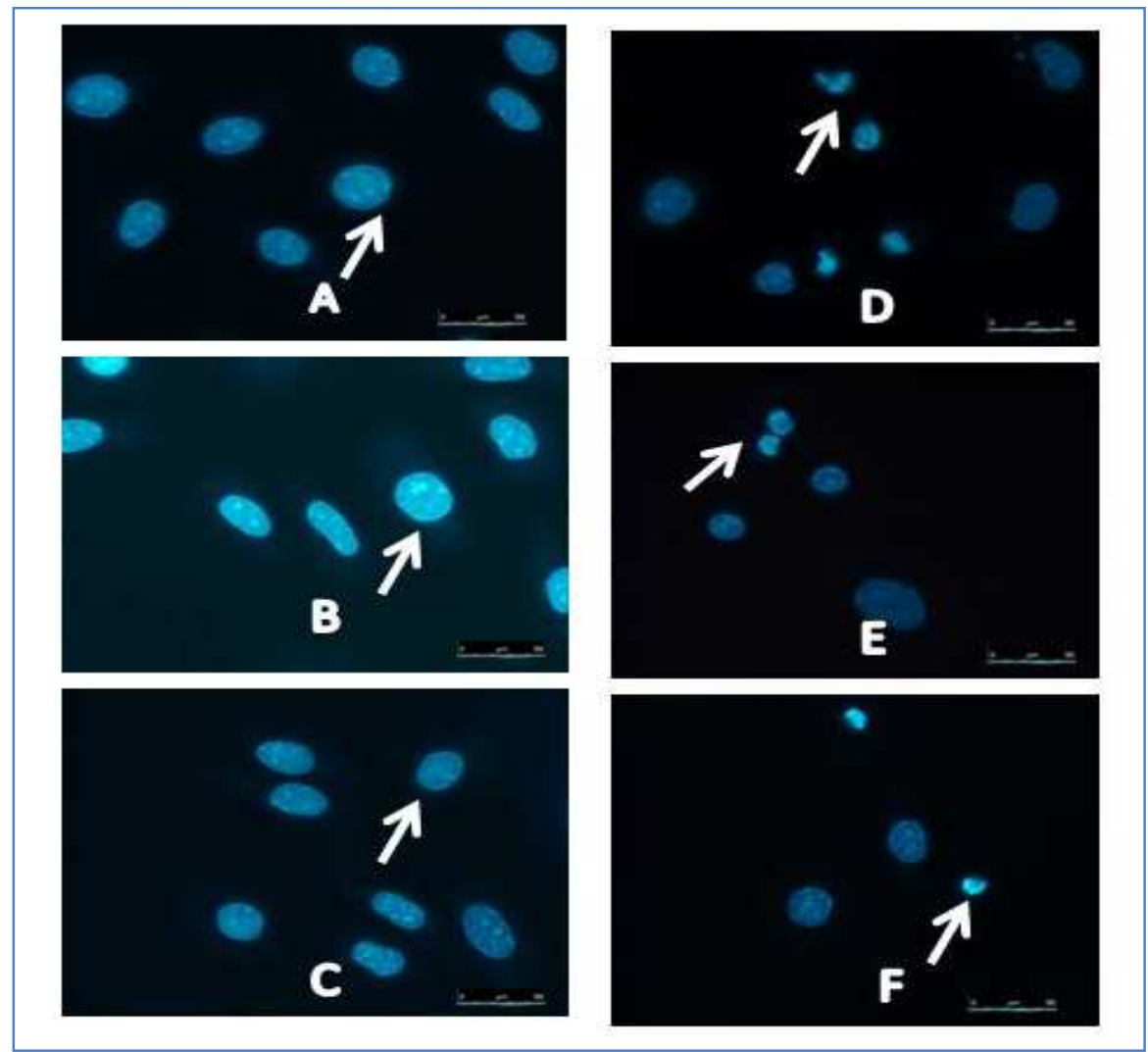

Fig. 3: Nuclear morphology of SiHa cells studied under a fluorescence microscope. Untreated sets with ovoid shaped nuclei (A, B, C) and sets treated with CLC for $24 \mathrm{~h}$, showing (D, E, F) eroded nuclear morphology

Note: SiHa cells were treated with Chaetomorpha linum chloroform fraction (CLC) and stained with hoechst 33258 on poly-lysine coated coverslips. Scale represents $50 \mu \mathrm{m}$

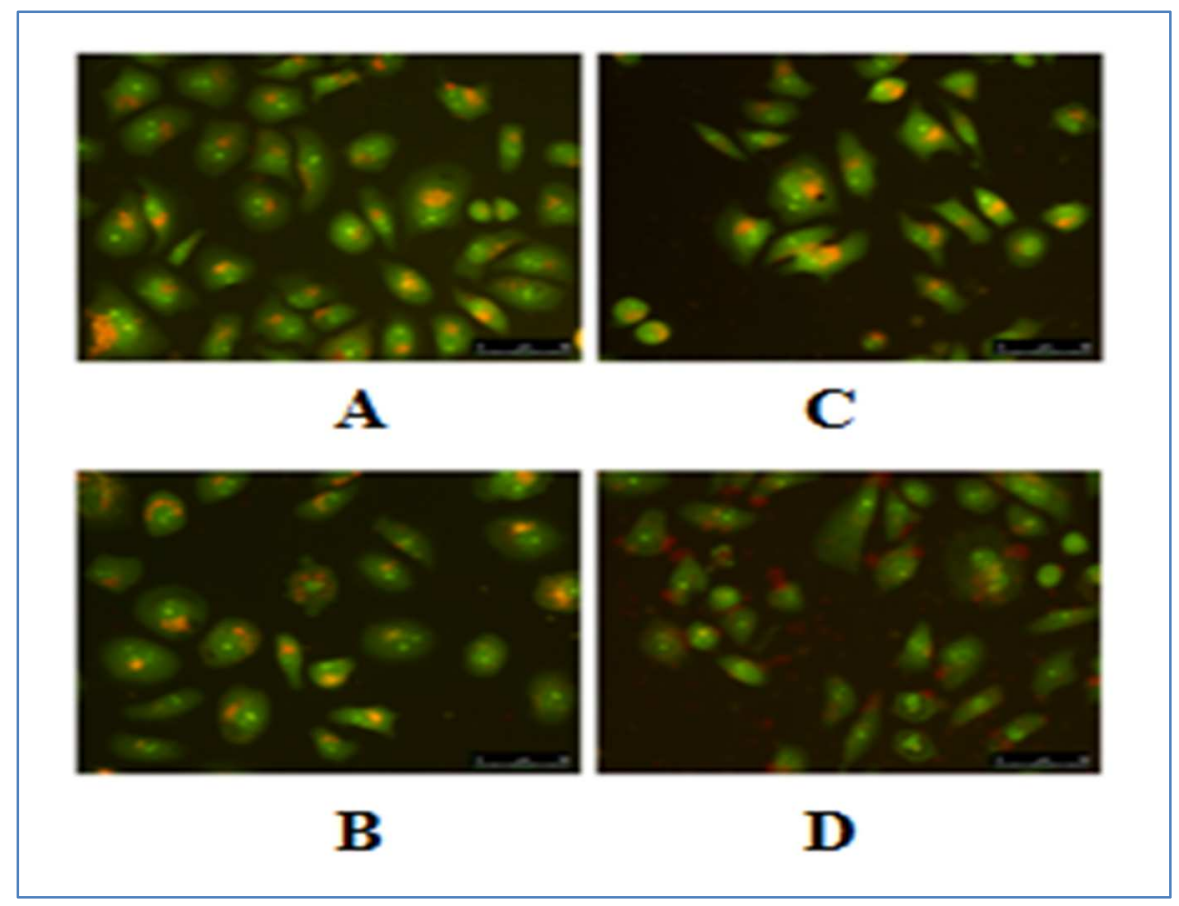

Fig. 4: Detection of acidic vacuoles in SiHa cells studied under a fluorescence microscope. Compared to untreated set (A, B); appearance and accumulation of acidic autophagic vacuoles with diffused red dye (acridine orange) intensity can be observed in $24 \mathrm{~h}$ treated sets; CLC (C, D)

Note: SiHa cells were treated with Chaetomorpha linum chloroform fraction (CLC). In the untreated set, nucleus and cytoplasm were stained green and acidic compartments as bright red specs. Scale represents $50 \mu \mathrm{m}$. 


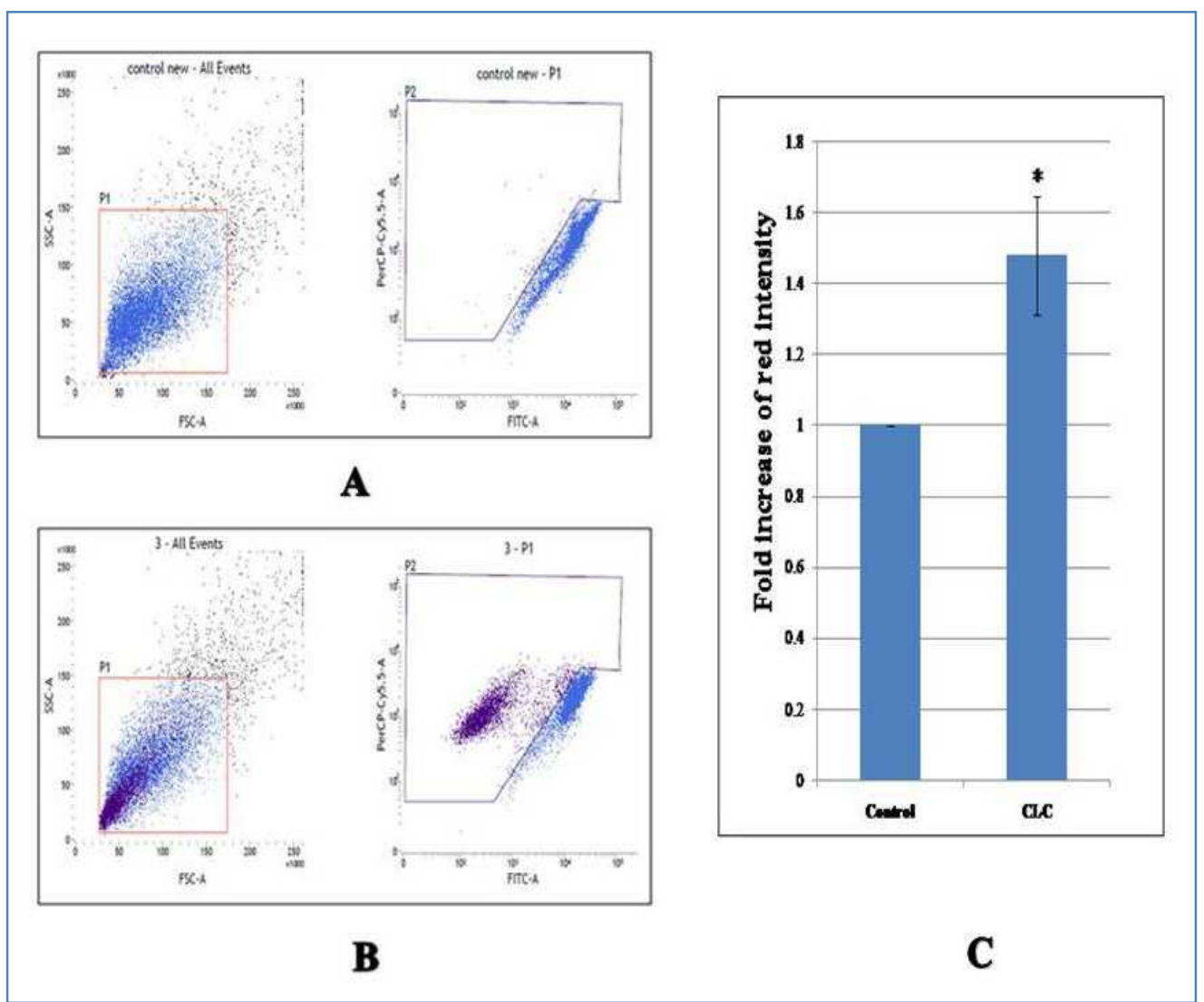

Fig. 5: FACS analysis of SiHa cells, stained with acridine orange (AO). (A) untreated set, (B) $24 \mathrm{~h}$ treated set with Chaetomorpha linum chloroform fraction (CLC)

Note: Treated sets showing greater accumulation of $\mathrm{AO}$, compared to untreated set; indicating increased autophagosome formation induced by the treatments. Bar graph showing the increased population of cells with $\mathrm{AO}$ ( ${ }^{*}$ represents significance level at $\left.\mathrm{p}<0.01\right)$ (C). Values are expressed as mean \pm SD of three independent experiments $(n=3)$. FACS data were analysed by Flowlogic software

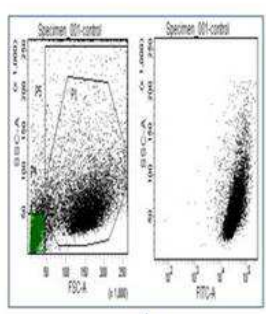

$\mathbf{A}$

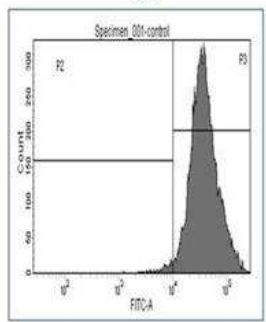

B

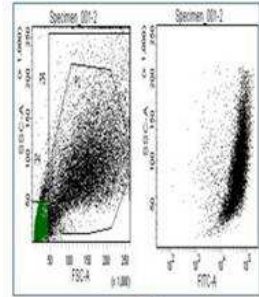

C

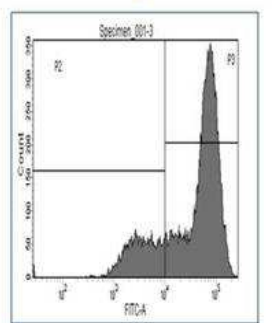

D

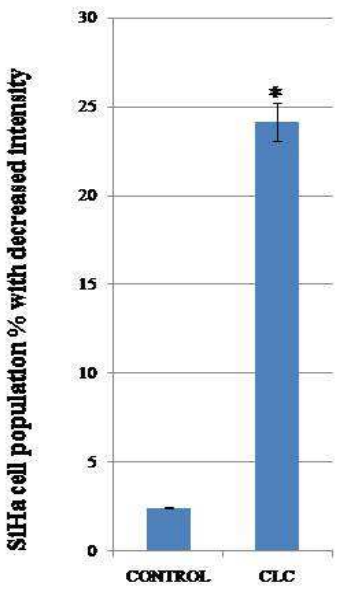

$\mathbf{E}$

Fig. 6: FACS analysis of mitochondrial membrane potential assay by Rhodamine 123 (Rh 123) stained SiHa cells. Untreated set (A, B), cells treated with Chaetomorpha linum chloroform fraction (CLC) for $24 \mathrm{~h}$ (C, D). Bar graph showing significant changes in mitochondrial membrane potential in treated sets $(*$ represents significance level $p<0.01)$ (E)

Note: Values are expressed as mean \pm SD of three independent experiments $(n=3)$. FACS data were analysed by Flowlogic software 
Wound healing assay revealed the anti-proliferative activity of the potent algal extract of Chaetomorpha. In the untreated set, cell mass proliferation was clearly evident at the site of the scratch mark. In the treated set, no such migration was evident after $24 \mathrm{~h}$ (fig.8). That indicated that the chemical components of the algal extract have antiproliferative and cytotoxic potential towards cervical cancer cells.

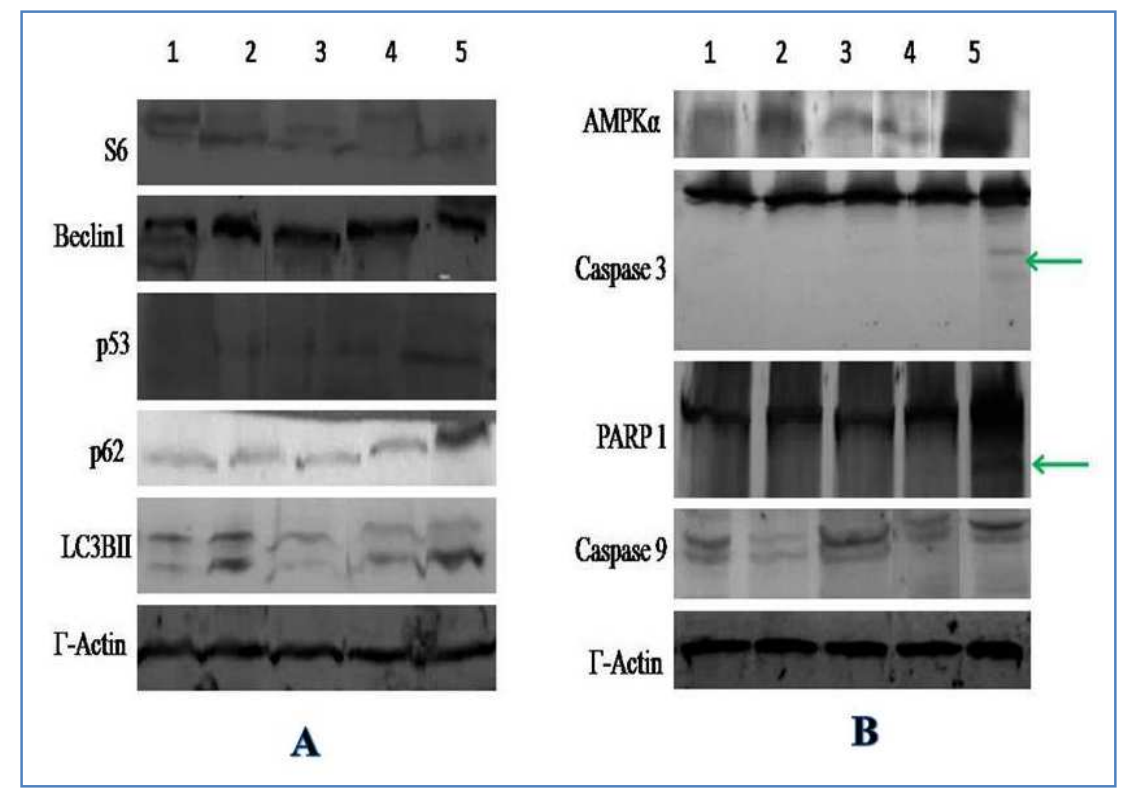

Fig. 7: Protein expression profiling for-S6, Beclin1, p53, p62, light chain 3BII (LC3BII) and $\gamma$-actin (A); 5' AMP-activated protein kinase $\alpha$ (AMPK $\alpha$ ), Caspase 3, Poly [ADP-ribose] polymerase 1 (PARP1), Casapse 9 and $\gamma$-actin (B). Lane 1: Control set, lane 2: Autophagy positive control (induced by $3 \mathrm{~h}$ starvation), lane 3:3-methyladenine (3-MA), lane 4:3MA with Chaetomorpha linum chloroform fraction (CLC) and lane 5: Treated with CLC

Note: Green arrows indicate cleaved products

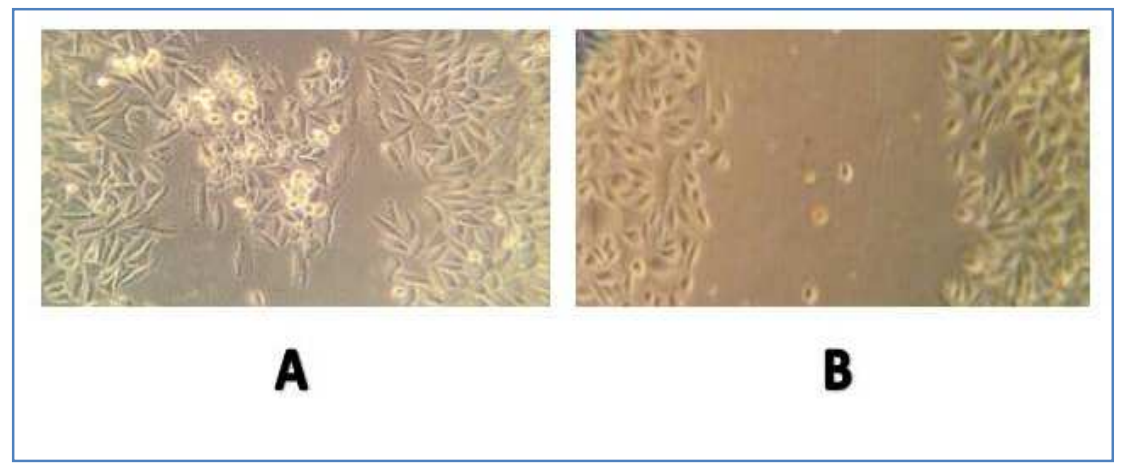

Fig. 8: Wound healing assay after a scratch was made on SiHa cell monolayer culture untreated set (A) diffused cell mass proliferation was evident with a compound microscope (X40), set treated with CLC for $24 \mathrm{~h}$ (B) no cell proliferation was observed

The preliminary Qualitative study indicated the presence of saponin, glycosides, steroid, alkaloid and flavonoid in CLC fraction.

During GCMS analysis air dried extracts were dissolved with DCM. In CLC, the presence of 3-formyl-napthyl-pyridone and 2-methyl-3oxovaleric acid as the major compounds were determined by GCMS study along with silanol, ethanimidic acid, eicosane (table 1).

\section{DISCUSSION}

Algae are rich in phytochemicals. Due to this rich chemical diversity, they are considered as good sources of biomedicine. In the present study, the cytotoxic potential of the chloroform fraction of Chaetomorpha linum (CLC) and the death pathway involved was validated. CLC extract induced cell death to the SiHa cells with an $\mathrm{IC}_{50}$ dose of $247.3 \mu \mathrm{g} / \mathrm{ml}$ with a low cytotoxicity towards the normal cells [14]. Cell cycle analysis with the respective $\mathrm{IC}_{50}$ dose has shown a comparatively higher percentage of cells in sub-G0 in the treated set.
The result indicates that the treatment causes no change in the cell cycle progression but causes some damage within the cells leading towards death. In the treated set no cell migration or proliferation was observed in the wound healing assay within $24 \mathrm{~h}$. This clearly indicates that CLC not only have cytotoxic properties to the SiHa cells but the extract is also able to inhibit the cell proliferation.

The cytotoxic and antiproliferative properties of CLC clearly indicate that due to the presence of some active components in the extract, it is able to trigger cell death mechanism in SiHa.

Microscopic observation of hoechst stained cells showed condensed and eroded nuclei in the treated sets, indicating DNA damage. But no fragmented DNA was observed in DNA laddering assay. At the same time, treated sets showed membrane disruption and lower mitochondrial membrane potential. This hampers ATP production and induced autophagic cell death in SiHa cells through AMPK dependent pathway. 
For a better understanding of molecular mechanism of cell death pathway induced in SiHa cells by CLC, the presence of autophagic vacuoles and relevant proteins were studied. The result points towards an intriguing finding.

Reports of algal metabolites inducing autophagic cell death in different cancer cell lines are available. Two green algae Rhizoclonium riparium and Enteromorpha intestinales were found to induce autophagy in SiHa cells [12].
Autophagosome formation in CLC treated SiHa cells were observed after $\mathrm{AO}$ staining. $\mathrm{AO}$ is a metachromatic dye, cationic and lipophillic in nature. The protonated form of the dye tends to accumulate into cellular organelles with an acidic $\mathrm{pH}$. Cytoplasm and nucleus appear bright green and acidic cellular compartments like lysosome appears bright red. In treated sets, a diffused red colored region indicating the fusion of acidic compartments to form autophagosomes. FACS analysis showed the increased population of cells in P2 region with higher accumulation of $\mathrm{AO}$ dye compared to the control set.

Table 1: Compounds identified by GC-MS analysis

\begin{tabular}{lll}
\hline Compounds identified in Chaetomorpha linum chloroform fraction (CLC) & & Peak area percentage \\
\hline Name of compounds & Retention time & 1.36 \\
\hline Silanol, trimethyl-, carbonate (2:1) & 5.168 & 0.98 \\
1,1-Dibromo-3-chloropropanone & 5.131 & 2.19 \\
Tris(trimethylsilyl)borate & 5.224 & 0.64 \\
Glycine, N-(1-oxopropyl)-N-(trimethylsilyl)-,trimethylsilyl ester & 5.425 & 5.40 \\
Tris(trimethylsilyl)carbamate & 6.000 & 6.61 \\
Methyltris(trimethylsiloxy)silane & 6.125 & 1.71 \\
Thieno[2,3-b]pyridin-3-amine, 4,6-dimethyl-2-phenylsulfonyl- & 6.257 & 2.01 \\
Propanoic acid, 2-[(trimethylsilyl)oxy]-, trimethylsilyl ester & 6.519 & 2.79 \\
Ethanimidic acid, N-(trimethylsilyl)-, trimethylsilyl ester & 6.821 & 17.81 \\
2-Methyl-3-oxovaleric acid, 0,0'-bis(trimethylsilyl)- & 7.226 & 2.51 \\
2-Butenoic acid, 3-methyl-2-[(trim ethylsilyl)oxy]-, trimethylsilyl ester & 7.334 & 0.25 \\
1H-1,3-Benzimidazole-5,6-dicarbonitrile,1-phenyl-i & 7.408 & 1.06 \\
4,6-Dioxa-5-aza-2,3,7,8-tetrasilanonane, 2,2,3,3,7,7,8,8-octamethyl- & 8.008 & 6.07 \\
1-Propanone, 1,3-diphenyl-3-(trimethylsilyl)- & 9.009 & 16.95 \\
3-Formyl-1-(1-naphtyl)-2(1H)-pyridone & 9.203 & 0.23 \\
Acetamide, 2,2,2-trifluoro-N-(trimethylsilyl)- & 10.454 & 0.72 \\
2-(4-Tert.-butylbenzylthio)-5-chloro-1H-benzimidazole & 11.054 & 1.43 \\
Glycerol, tris(trimethylsilyl) ether & 11.104 & 0.64 \\
Hexanoic acid, 6-chloro-,trimethylsilyl ester & 12.251 & 0.33 \\
Octane, 1,8-bis[4-(trimethylsilylcarbonyl)phenyl]- & 12.543 & 0.87 \\
1,3-Dimethylcyclopentanol & 13.252 & 1.70 \\
Trisiloxane, 1,1,1,5,5,5-hexamethy l-3,3-bis[(trimethylsilyl)oxy] & 15.777 & 1.82 \\
Hexadecane & 18.500 & 1.05 \\
2-tert-Butyl-6-methylphenol, O-tert-butyldimethylsilyl & 19.432 & 7.61 \\
Tetradecanoic acid, trimethylsilyl ester & 22.083 & 1.07 \\
Eicosane & 23.198 & 3.64 \\
cis-9-Hexadecenoic acid, trimethylsilyl ester & 24.941 & 0.77 \\
Octacosane & 31.379 &
\end{tabular}

As both the experiments with AO point towards autophagic cell death, expression of some hallmark protein of autophagic pathway was studied. Expression of LC3B was studied by immunoblotting. An enhanced expression of LC3BII, a marker protein for autophagic cell death was observed in the treated cells. LC3B is expressed in all cells as a full-length soluble protein, after autophagy induction, it is proteolytically cleaved to LC3BI. It is then conjugated with PE to form LC3BII. It is found in both the external and internal surfaces of autophagosomes and plays an important role in the hemifusion of membranes and selection of the cargo for degradation [22]. Therefore, increased expression of LC3BII signifies the advanced stage of autophagy.

Increased expression of p53 in both treated and starved sets indicates the positive role of p53 here. p53 is also reported to influence autophagic cell death by activating SQSTM/p62 and LC3BI lipidation [23]. p53 was also reported to downregulate mTOR1 (anti-autophagic protein) and up-regulate AMPK. AMPK upregulates TSC1 and TSC2 which inhibit Rheb, which results in decreased expression of mTOR1 complex [21]. Overexpression of p62 in treated and starved sets, was observed. P62 increases the maturation of LC3BII [24], is one of the most important hallmark protein for autophagy. S6 expression is totally absent in treated sets, S6 sometime down regulates pULK1 expression by inhibiting autophagy.

To study the AMPK/mTOR signalling pathway involved in the cell death induction, expression of AMPK (a major sensor for cellular energetic), Caspase 3, PARP1 and Caspase 9 expression were studied in the CLC treated cells, starved cells and 3-MA-treated cells (negative control). Results indicated that, AMPK dependent pathway was involved in inducing autophagy. At the same time expression of Caspase 3 and PARP1 increased significantly. Expression of cleaved Caspase 3 and PARP1 points towards the involvement of apoptotic pathway in the treated set whereas in autophagy positive sets (induced by starvation) the cleaved product expression was not observed. In response to death stimuli certain death receptors are activated and the mitochondrial membrane potential changes; resulting in the release of Cyt-C and Apaf proteins. This then activates Caspase 3. Caspase 3 then cleaves and activates PARP1 which is responsible for DNA repairing. Here in the treated set, both the expression of cleaved products of Caspase 3 and PARP1 indicates that the death pathway shows an interaction between apoptosis and autophagy.

The cleaved product of Caspase 9 was observed by immunoblotting. Caspase 9 sometime activates Caspase 3 inducing apoptosis [25]. It may activate Cathepsin D when lysosomal pH becomes very acidic, leading towards autophagic death.

Phytochemicals present in CLC might have initiated the mechanism leading towards cell death in SiHa. Presence of saponin, glycosides, phenol, alkaloid and steroids were determined by qualitative assay. GCMS analysis of CLC has shown the presence of some bioactive compounds such as benzimidazole derivatives, eicosane, octacosane and some fatty acids. Octacosane and eicosane are reported to have mosquitocidal and antifungal activities [26-27]. Antimicrobial, antifungal, the anticancerous activity of benzimidazole derivatives are already reported [28-30]. Anti-cancerous activity of hexadecanoic acid (palmitic acid) and octadecanoic acids (stearic acid) are already established [31-32]. Most of the fatty acids are reported to induce cell death by apoptosis. 


\section{CONCLUSION}

Conventional phytochemical assays and GCMS indicated the presence of several bioactive compounds. When the cells were treated with chloroform fraction of this phyto compound rich algal extract, it inhibited cell proliferation and induced cell death, which were subsequently validated through several experiments.

All the experiments clearly showed that compound(s), present in the chloroform extract of Chaetomorpha linum were able to induce oxidative stress in the SiHa cells and this reactive oxygen species might have decreased the ATP level which in turn activated AMPKs. At the same time cleaved Caspases and PARP1 were observed, all these findings indicated that cell death occurs due to the interaction between apoptosis and autophagy.

\section{ACKNOWLEDGEMENT}

The authors wish to thank WB-DST [sanc. No-410 (Sanc.)ST/P/S and T/9G-14/2012,03.09.2015] for the financial assistance; DST-FIST for providing GC-MS facility. We would also like to thank Department of Botany, Centre of Advanced Study (CAS-UGC), the University of Calcutta for partially supporting the research.

\section{AUTHORS CONTRIBUTIONS}

Conceived and designed the experiments: RK.

Performed the experiments: IM.

Analyzed the data: SP, IM, RK.

Contributed reagents/materials/analysis tools: RK.

Wrote the paper: RK, SP, IM

\section{CONFLICT OF INTERESTS}

All authors declare has no conflict of interest

\section{REFERENCES}

1. Faulkner DJ. Marine natural products. Nat Prod Rep 2001;18:1-49.

2. Al-Saif SSA, Abdel-Raouf N, El-Wazanani HA, Aref IA. Antibacterial substances from marine algae isolated from Jeddah coast of Red sea, Saudi Arabia. Saudi J Biol Sci 2014;21:57-64.

3. Kolanjinathan K, Ganesh P, Govindarajan M. Antibacterial activity of ethanol extract of seaweeds against fish bacterial pathogens. Eur Rev Med Pharmacol Sci 2009;13:173-7.

4. Princely S, Dhanaraju MD. Assessment of phytochemical constituent in vitro antimicrobial and antioxidant potential of Ulva extracts from Vishakhapatnam coast. Asian J Pharm Clin Res 2017;10:87-95.

5. Sheu JH, Huang SY, Wang GH, Duh CY. Study on cytotoxic oxygenated desmosterols isolated from the red alga Galaxaura marginata. J Nat Prod 1997;60:900-3.

6. Kwon MJ, Nam TJ. A polysaccharide of the marine alga Capsosiphon fulvescens induces apoptosis in AGS gastric cancer cells via an IGF-IR-mediated PI3K/Akt pathway. Cell Biol Int 2007;31:768-75.

7. Fischel JL, Lemee R, Formento P, Caldani C, Moll JL, Pesando D. Cell growth inhibitory effects of caulerpenyne, a sesquiterpenoid from the marine alga Caulerpa taxifolia. Anticancer Res 1995;15:2155-60.

8. Barbier P, Guise S, Huitorel P, Amade P, Pesando D, Briand C. Caulerpenyne from Caulerpa taxifolia has an antiproliferative activity on tumor cell line SK-N-SH and modifies the microtubule network. Life Sci 2001;70:415-29.

9. Harada H, Noro T, Kamei Y. Selective antitumor activity in vitro from marine algae from Japan Coasts. Biol Pharm Bull 1997;20:541-6.

10. Ahmad A, Usman $H$, Natsir $H$, Karim A. Isolation and characterization of a bioactive protein from green algae Halimeda macrobola acting as antioxidant and anticancer agent. Am J Biomed Life Sci 2014;2:134-40.

11. Moo-Puc R, Robledo D, Freile-Pelegrin Y. In vitro cytotoxic and antiproliferative activities of marine macroalgae from Yucatán, Mexico. Cienc Mar 2009;35:345-58.
12. Paul S, Kundu R. Antiproliferative activity of methanolic extracts from two green algae, Enteromorpha intestinalis and Rizoclonium riparium on HeLa cells. DARU J Pharm Sci 2013; 21:72.

13. Forman D, Bray F, Brewster DH, Gombe Mbalawa C, Kohler B, Ferlay J, et al. Cancer incidence in five continents, Vol. X (electronic version) Lyon, IARC; 2013. Available from: http://ci5.iarc.fr [Last accessed on 01 Nov 2013]

14. Majumder I, Chatterjee S, Kundu R. A study of the antiproliferative potentiality of some major macroalgae from sundarbans on cervical cancer cell line. J Algal Biomass Utln 2015;6:212.

15. Kang H, Alvarado AS. Flow cytometry methods for the study of cell-cycle parameters of planarian stem cells. Dev Dyn 2009;238:1111-7.

16. Hu H, Ahn HN, Yang X, Lee YS, Kang KS. Ganoderma lucidum extract induces cell cycle arrest and Apoptosis in mcf-7 human breast cancer cell. Int J Cancer 2002;102:250-3.

17. Pozo Guisado E, Alvarez Barrientos A, Mulero Navarro $S$, Santiago Josefat B, Fernandez Salguero PM. The antiproliferative activity of resveratrol results in apoptosis in MCF-7 but not in MDA-MB-231 human breast cancer cells: cellspecific alteration of the cell cycle. Biochem Pharmacol 2002;64:1375-86.

18. Hamori E, Arndt Jovin DJ, Grimwade BG, Jovin TM. Selection of viable cells with known DNA content. Cytomet 1980;1:1980.

19. Loken MR. Simultaneous quantitation of hoechst 33342 and immunofluorescence on viable cells using a fluorescence activated cell sorter. Cytomet 1980;1:136-42.

20. Trease GE, Evans WC. Pharmacognosy. $11^{\text {th }}$ ed. London: MacMillan Publishers Ltd.; 1989. p. 60-75.

21. Feng Z, Zhang H, Levine AJ, Jin S. The coordinate regulation of the p53 and mTOR pathways in cells. Proc Natl Acad Sci USA 2005; 102:8204-9.

22. Glick D, Barth S, Macleod KF. Autophagy: cellular and molecular mechanisms. J Pathol 2010;221:3-12.

23. Tang J, Di J, Cao H, Bai J, Zheng J.p53-mediated autophagic regulation: A prospective strategy for cancer therapy. Cancer Lett 2015;63:101-7.

24. Kim YS, Shin JH, Bae MK. Autophagy activity in pulmonary metastatic tumor tissues from colorectal cancer: a pilot study. Yonsei Med J 2014;55:1484-8.

25. Marks N, Berg MJ, Guidotti A, Saito M. Activation of caspase-3 and apoptosis in cerebellar granule cells. J Neurosci Res 1998;52:326-41.

26. Rajkumar S, Jebanesan A. Mosquitocidal activities of octacosane from Moschosma polystachyum Linn. (lamiaceae). J Ethnopharmacol 2004;90:87-9.

27. Ahsan $T$, Chen J, Zhao X, Irfan $M, W u$ Y. Extraction and identification of bioactive compounds (eicosane and dibutyl phthalate) produced by Streptomyces strain KX852460 for the biological control of Rhizoctonia solaniAG-3 strain KX852461 to control target spot disease in tobacco leaf. AMB Express 2017;7:54.

28. Ansari KF, Lal C. Synthesis and evaluation of some new benzimidazole derivatives as potential antimicrobial agents. Eur J Med Chem 2009;44:2294-9.

29. Kristina S, Marijeta M, Katja E, Ivan S, Magdalena G, Grace KP, et al. Synthesis, the antiviral and antitumor activity of 2substituted-5-amidino-benzimidazoles. Bioorg Med Chem 2007;15:4419.

30. Sondhi SM, Rani M, Sigh J, Roy P, Agrawal SK, Saxena AK. Solvent-free synthesis, anti-inflammatory and anticancer activity evaluation of tricyclic and tetracyclic benzimidazole derivatives. Bioorg Med Chem Lett 2010;20:2306.

31. Mu YM, Yanase T, Nishi Y, Tanaka A, Saito M, Nawata H, et al. Saturated FFAs, palmitic acid and stearic acid, induce apoptosis in human granulosa cells. Endrocrinology 2001;142:3590-7.

32. Ulloth JE, Casiano CA, De Leon M. Palmitic and stearic fatty acids induce caspase-dependent and-independent cell death in nerve growth factor differentiated PC12 cells. J Neurochem 2003;84:655-68. 